Viso - Cadernos de estética aplicada Revista eletrônica de estética

ISSN 1981-4062

№ 8, jan-jun/2010

http://www.revistaviso.com.br/

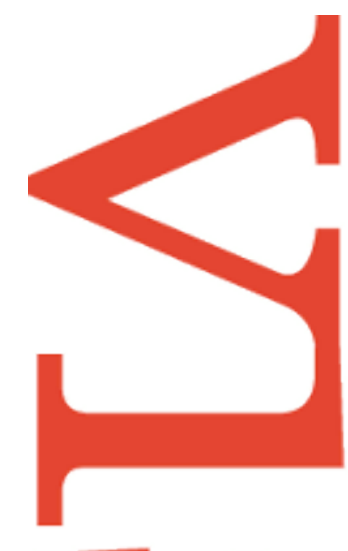

\title{
A ópera a que assistimos: um estudo de caso
} Claudio Reis Vieira 


\section{RESUMO}

A ópera a que assistimos: um estudo de caso.

Esse artigo discute as relações de produção que caracterizam as montagens operísticas contemporâneas a partir do programa "Ópera no cinema", que trasmite récitas do Metropolitan Opera House, em alta definição e ao vivo, para salas de cinema em diferentes países. Duas montagens desse programa - Lucia de Lammermoor e La Sonnambula, de Donizetti - são analisadas ao lado da versão de Dimitri Tcherniakov para o Macbeth, de Verdi, realizada pela Ópera de Novossibirski em parceria com a Opéra National de Paris.

Palavras-chave: música erudita - ópera - Verdi - Donizetti

\section{ABSTRACT}

The opera we watch: a case study

This paper takes the Metropolitan Opera House HD live broadcasting program as a starting point for discussing contemporary opera production. It analyzes two MET stagings - for Donizetti's Lucia de Lammermoor and La Sonnambula - along with Dimitri Tcherniakov's version of Verdi's Macbeth, a co-production of Novossibirski's Opera House and Opéra National de Paris.

Keywords: classical music - opera - Verdi - Donizetti 


\section{VIEIRA, C. R. "A ópera a que assistimos: um estudo de caso". In: Viso: Cadernos de estética aplicada, v. IV, n. 8 (jan-jun/2010), pp. 10-22.}

DOI: $10.22409 / 1981-4062 / v 8 i / 82$

Aprovado: 04.03.2010. Publicado: 10.07.2010.

(C) 2010 Claudio Reis Vieira. Esse documento é distribuído nos termos da licença Creative Commons Atribuição-NãoComercial 4.0 Internacional (CC-BY-NC), que permite, exceto para fins comerciais, copiar e redistribuir o material em qualquer formato ou meio, bem como remixá-lo, transformá-lo ou criar a partir dele, desde que seja dado o devido crédito e indicada a licença sob a qual ele foi originalmente publicado.

Licença: http://creativecommons.org/licenses/by-nc/4.0/deed.pt_BR

Accepted: 04.03.2010. Published: 10.07.2010.

(C) 2010 Claudio Reis Vieira. This document is distributed under the terms of a Creative Commons Attribution-NonCommercial 4.0 International license (CC-BY-NC) which allows, except for commercial purposes, to copy and redistribute the material in any medium or format and to remix, transform, and build upon the material, provided the original work is properly cited and states its license.

License: http://creativecommons.org/licenses/by-nc/4.0/ 
Casar ópera e cinema: idéia quase tão antiga quanto este mundo. Muitos esforços, artisticamente frustrados. Alguns melhores, de cineastas importantes: De Mille e Lubitsch, por exemplo, filmes silenciosos; depois, Ponnelle, Losey, Bergman, Zeffirelli, Rosi, D'Anna e Jacquot, adaptações autorais. Também muitas filmagens diretas de montagens em curso - "filmes-de-ópera".

Rio de Janeiro, 2009. Fechado o Teatro Municipal. Nós, os que apreciamos e não podemos viajar, sem ópera. Inteligente, a empresa Moviemobz cria alternativa: "Ópera no Cinema". Primeiro ensaio em fevereiro, março. Outro iniciado em novembro. Ao todo 15 títulos, diversos cinemas.

2009, "Ano da França no Brasil". Em outubro, outra oportunidade: "Ópera na Tela", 15 filmes-de-ópera, outros sobre elas, balés e a música chamada erudita (sic). Nos Correios e no Instituto Moreira Salles.

Contraste do panorama: habitualmente, meia dúzia apenas de programas no Municipal. Colheita boa, portanto. Será?

"Ópera no Cinema" são vesperais do Metropolitan Opera House de Nova lorque. Há cerca de três anos vêm sendo exibidos na Europa. Filmagens transmitidas em tempo real. Há notícia de sucesso: outros teatros importantes propensos a explorar o caminho. Por exemplo, produções filmadas do Teatro alla Scala, de Milão, são apresentadas regularmente no Museu do Louvre.

Filmes-de-ópera não são feitos de uma arte, nem de outra. Não são filmes: falta-lhes edição. Não são montagens operísticas: a câmera registra apenas fração da plenitude encenada. No passado, mal sucedidos. Revalorizados hoje pelas técnicas de alta qualidade em gravação e reprodução, de som e imagem.

Não se trata, só, de evolução tecnológica. O renascimento do filme de ópera tem motivação econômica.

Ópera, nos Estados Unidos, é investimento privado; mecenato e bilheteria representam mais de $90 \%$ dos orçamentos dos teatros de ópera. Sob impacto de "A Crise", penúrias. Reduções drásticas das contribuições e receitas de ingressos levaram a cancelamentos de produções da temporada 2009/2010 (Connecticut Opera, Washington Opera). Mesmo em Nova lorque (Opera Orchestra of New York e New York City Co. - rival do MET, instalada ao lado, no Lincoln Center). Recorreu-se até ao pleito de subsídio governamental, sob proteção de lei prevista para casos extremos (Baltimore Opera Co.). Naquele mundo, uma heresia! 
Na Europa, contexto oposto, subvenção é regra. Antes de "A Crise" o setor já vivia crises - sem maiúsculas - em muitos países: custos de produção crescentes, subsídios decrescentes; mesmo lá onde se inventou a ópera, na Itália, a tradição sufocada — um descalabro.

Para a enfermidade, há agente de conjuntura: a praga neoliberal, doença senil do capitalismo - permita-se a analogia para qualificar. ${ }^{1}$

Não só. Existe também, de ambos os lados do Atlântico, razão estrutural: a concorrência de outros tipos de espetáculo. Esta causa, não a farão desaparecer, por si sós ou combinados, eventual revigoramento do Estado, níveis subvencionais ou de patrocínio aumentados, bilheterias ampliadas. ${ }^{2}$

Buscaram-se alternativas.

Estratégia recorrente: repartir, entre dois ou três teatros, custos "fixos" de produção cenários, figurinos - e exibir a montagem, sucessivamente, em centros diferentes. Elencos distintos - principal custo variável - multiplicam a oferta: cada remontagem, outro espetáculo. Novas platéias e possíveis reincidentes: quem viu o primeiro, talvez se anime a deslocamento para apreciar o segundo - se aquele foi ruim, este pode ser bom; se foi bom, quiçá valerá a pena conferir (a indústria do cinema adaptou o expediente: remakes tornam-se corriqueiros, porque o original fez muito sucesso ou porque nenhum).

Segunda frente: incorporar recursos tecnológicos modernos, não obstante obsolescência crescentemente rápida. Há vinte anos discutia-se a utilização de legendas nas casas de ópera - hoje, lugar-comum; assim também a projeção de imagens, mesmo com os cantores presentes no palco. Lembrar ainda aplicações do vídeo: em tecnologia logo renovada (Betamax, VHS, LD, DVD, Blue-Ray, o que mais vier), não reproduzem o espetáculo original, porquanto mediados pelo diretor de TV; em compensação, editados, como o cinema, minimizam pontuais deficiências, combinando tomadas de várias récitas do mesmo espetáculo. Deste modo alcança-se mercado mais amplo: dos que não puderam ou não quiseram assistir ao vivo; e dos que o fizeram, mas querem fruir de novo, por lembrança e associação. No capítulo da integração da modernidade técnica, o filão mais recente: a transmissão em HD e, na sua trilha, o renascimento do filme-deópera. A exploração, como de esperar, iniciada pelo maior teatro lírico estadunidense. Estaria a produção de ópera, também lá, em crise mais antiga? Ou teria sido apenas a descoberta de novo campo de negócios?

Terceira opção de combate, já em uso generalizado: "atualização" dos enredos das óperas - preservados libretos e música - com transposição de épocas, figurinos, perfis psicológicos de personagens, etc.

Entretanto, os expedientes todos não asseguram a continuidade do gênero em trajetória tranqüila. 
A ópera surgiu no início do século XVII na Camerata Fiorentina, grupo de eruditos a serviço de nobres. Homens do Renascimento, primeiro produto intelectual da burguesia em formação, queriam reinventar o teatro grego. Achavam insulsa a arte cênica da época. Diagnosticaram a falta do canto; julgavam-no presente todo o tempo, ao longo da representação da tragédia grega clássica - um equívoco. Pelo engano, puseram música a serviço do texto, buscando aumentar-Ihe a expressividade. Inventaram a ópera, que chamavam dramma per musica.

De então ao século $\mathrm{XX}$, a primazia do texto ou da música instituiu-se em dilema para os ligados na ópera. Da encenação, os gregos pouco cuidavam. Por razões próprias à origem e circunstâncias de realização de seu teatro. A ópera, quase sempre, também não. Apenas texto e música importavam. ${ }^{3}$

No entanto o século $X X$ foi época de influências impactantes em todas as formas culturais. Entre outros elementos do contexto: técnicas constantemente aperfeiçoadas de armazenamento, reprodução e distribuição de sons e imagens; potencialidades crescentes de público ampliado, também, pela eficiência de transportes e comunicações. Momento de condições excepcionais conjugadas. E, contraditoriamente ou nem tanto, tempo de reação anti-renascentista: nas artes visuais, na música, também na dramaturgia e na ópera. Tempo de sociedade hiperinformada a engatinhar, em infância turbulenta e desordenada. Com ela, característica nova, obsedante, impregnando quase toda manifestação cultural: o entretenimento desinteligente.

Por isso, tempo de crise estrutural para a ópera, à qual não bastam os expedientes produções compartilhadas, incorporações tecnológicas, atualizações. Inevitável adaptar a montagem operística ao novo tempo. Então, um elemento começa a ser valorizado acima do texto, acima da música: a montagem. Com ela, o diretor. Um componente que nada tinha a ver com o projeto original. Porém apropriado para enquadrar a ópera na cultura do entretenimento desinteligente. Inevitável. Imperativo de sobrevivência.

$* * *$

Vetor de desinteligência no entretenimento: o culto ao Efêmero. Vírus capitalista, contamina o que o homem produz. De tudo reduz a vida para tudo refazer, porque consumir (destruir a utilidade, em geral ao custo do suporte físico dela) é imprescindível ao crescimento do capital. Ampliada, apenas e cada vez mais, a vida útil - útil para o capital - do homem que consome. A do resto, sempre encurtada, inclusive a dos outros homens, os que não consomem ou o fazem muito pouco. Sob tal pressão, as vivências humanas tendem a Efêmeros. As que o são por natureza mesma; e as que, não o sendo, se vão tornando. Contaminações do Efêmero na arte: instalações, intervenções, provocações. Na literatura (geralmente): bestsellers. Em modos e costumes: danças "de salão" nas quais os parceiros quase não se tocam — propriamente, não são pares, cada 
indivíduo sacoleja em frente a alguém num momento, logo em seguida em face de outro. Desde o transistor e a técnica digital, todo desenvolvimento tecnológico voltado à redução da vida útil, à substituição de produtos, à criação de novas pretensas "utilidades"; tudo, num átimo, feito velho, obsoleto, superado - menos a vida do ente consumista, protegida, cuidada, esticada.

Produto artístico mais efêmero é do palco: o Espetáculo. Paradigmático Espetáculo: o de música pop, com sua montagem associada ao som - a parafernália tecnológica, a coreografia e o hipnotizado aglomerado humano.

No fim do século XX, no XXI, inexorável: o espetáculo operístico mimetiza o Espetáculo paradigmático.

Há centros de formação lírica abrangendo a encenação. Mas, grande número de aclamados diretores, oriundos do teatro. Também atraídos cineastas de renome. Não raro sem instrução musical. Às vezes, sequer diletantes do gênero. O palco, apenas, importa. E vão-se tornando chefes do espetáculo. Regentes consagrados ainda dispõem de certa influência na concepção. Cantores, pouca - a menos das estrelas midiatizadas que, vezes poucas, dizem não. Deles, regentes e cantores, astros ou aspirantes a, depende, acima de tudo, o resultado lírico, a essência operística. Contudo os resenhistas, os comentaristas, dedicam à montagem mais da metade do espaço ou do tempo de que dispõem. Adiante se verá.

Cada vez mais amiudadas, as "atualizações" promovidas pelos diretores.

Algumas, meras alternativas a marcações originais dos libretos. Não raro, impostas por inerências ao espaço disponível no palco.

Outras, transposições de época, visando imprimir à montagem estilo mais ajustado ao gosto do encenador; ou sua visão original dos perfis psicológicos e motivações dos comportamentos das personagens. Nada a opor, se o ajustamento não vai de encontro à música. Pode ser de fato meritório, enriquecimento, redimensionamento da obra.

Contudo há atualizações com o propósito, explícito ou não, de resultarem em Espetáculos. Admitida é qualquer deturpação do sentido original da obra, julgada necessária para tanto.

Nos filmes-de-ópera das séries Ópera do Cinema e Ópera na Tela, em 2009, exemplos de três tipos de atualização: uma transposição de época que preserva a integridade operística da obra original; outra, em detrimento desta, elege o espetáculo como objetivo maior; terceira, que a vivifica, mesmo se apenas parcialmente bem-sucedida. 
Dentre as vesperais do MET em HD, exibidas no primeiro semestre, dois trabalhos do mesmo diretor, Mary Zimmerman4: Lucia de Lammermoor, de Donizetti e La Sonnambula, de Bellini. Em ambas realizações, muito boa a equipe musical, alguns cantores consagrados, outros em franca ascensão. ${ }^{5} \mathrm{Em}$ ambas as montagens, atualizações.

Lucia de Lammermoor (1835) tem libreto baseado em Walter Scott. ${ }^{6}$ Transcorre em fins do século XVII, na Escócia. Gira em torno da rivalidade entre dois clãs das Terras Altas. Ação transposta para a época dos autores, início do século XIX. A operação, embora sem porquê, não ofendeu o conteúdo dramático, não alterou os perfis psicológicos, preservou a linha comportamental. Obra-prima do belcantismo, Lucia já carrega, no original, elementos suficientes para a produção de espetáculos bem sucedidos; bastam bom-gosto e eficácia na cenarização (cenários, figurinos, iluminação), competência na direção de atores e bom nível de realização musical (cantores, coros, orquestra, regente).

La Sonnambula (1819) tem outra face. História campestre, de extrema simplicidade. Ingenuidade e desinformação de camponeses, em aldeia remota, sustentam a verossimilhança da trama. Época indefinida; mas há referências a um castelo e indicadores sociais caracterizadores de um campesinato livre, porém não proprietário (aldeões cultivam campos em regime de posse; lavoura e aglomerado urbano hospedaria, moinho, igreja - tudo se situa em domínios do castelo); presença também, como personagem importante, de um "conde", herdeiro de todas as terras. Música simples, em conformidade com o entrecho. No libreto, de Romani, ausência de paixões insopitadas; de ódios incontrolados; de intrigas avassaladoras. A partitura, belcantista, não consagra excesso de floreios. Não há grandes arrebatamentos; há suavidades. Bons intérpretes garantem boa música. Não asseguram boa montagem. Para tal, necessários ainda: respeito ao espírito da obra (sempre), soluções criativas na cenarização e excelente direção de atores. Assim a autenticidade será preservada. Pieguices serão prevenidas. E seduzido o público de hoje.

Opção adotada no espetáculo do MET: transformar a ação em um ensaio para estréia de nova montagem da ópera, supostamente a acontecer ali, no próprio teatro nova-iorquino. Multidões no palco: além do coro, partícipe na trama original, numerosos figurantes "desempenhando" funções apenas necessárias durante o suposto ensaio. Grande movimentação, todo o tempo. Direção de atores eficiente (todos os cantores, não só os protagonistas, "bons de palco"). E equivocada: no comportamento das "personagens" da ópera sendo ensaiada, dissimulações, pequenas licenciosidades (o tenor tentando "se aproveitar" do soprano). Nada a ver com a obra de Bellini. Resultado muito próximo de um "musical da Broadway". Um Espetáculo. 
Da Eurásia veio exemplo de transposição vivificante: uma atualização de Macbeth (1847), ópera de Verdi baseada na tragédia shakespeariana. Coprodução da Ópera de Novossibirsk, Sibéria, com a Opéra National de Paris. Realização de Dimitri Tcherniakov, responsável por tudo, exceto a música: concepção, cenários, figurinos, direção de atores. Até mesmo supervisão da filmagem, no intuito de assegurar o foco nos aspectos que considerava mais importantes em seu trabalho. Apresentada na Opéra Bastille em abril de 2009, deu origem a viva controvérsia. Um de seus entusiastas admiradores é Richard Martet, redacteur en chef de importante periódico especializado - Opéra Magazine, Paris (http://www.opera-magazine.com).

Recorro a passagens de seus textos.

Inicialmente, o editorial do $N^{\circ} 36$, janeiro, 2009. Relata suas impressões, após haver assistido à montagem na Rússia. As primeiras visões do palco deixaram-no receoso: em vez das feiticeiras do texto original - Piave e Verdi haviam convertido em um bando as três do texto inglês - , multidão, mas de pessoas, perambula, em capas de chuva, defronte a pequenas casas alinhadas; Lady Macbeth traja camiseta preta e guarda-pó bege; o esposo em camisa branca e calça cinza.

Depois tranquiliza-se:

[...] a coerência do método, a inteligência da direção de atores, as correspondências entre o texto e a música, bem como um jeito de se impor ao espectador sem enfará-lo nem agredi-lo, justificam cada gesto, cada imagem [...] O importante é que, com decisões discutíveis porém claramente assumidas - especialmente a de retirar toda a dimensão fantástica da trama e de fazer, dos dois personagens principais, um Senhor e uma Senhora iguais a Todo-Mundo, Tcherniakov oferece uma interpretação apaixonante das relações entre os esposos (amor, admiração, ressentimento, dependência...) e da engrenagem dos assassinatos (é de fato a sociedade, desde o início hostil a Macbeth, que the insufla a idéia de crime, para no final expulsá-lo como um malfeitor). Todas as referências tradicionais se embaralham: Lady Macbeth não é mais a única instigadora, Macbeth não é somente um fraco, manipulado pela mulher, o oprimido pode ser ao mesmo tempo o opressor, o carrasco e a vítima não são mais, necessariamente, quem acreditamos $[\ldots]^{7}$

Ao resenhar a apresentação, em Paris, Martet escreveu:

As decisões de Dimitri Tcherniakov, já dissemos e repetimos, são eminentemente discutíveis e não nos surpreendemos que assovios se tenham misturado a tonitruantes aplausos após a cortina final, na estréia. Mas elas têm o mérito duplo de serem claramente assumidas e defendidas com uma coerência implacável. É particularmente arriscado, por exemplo, extrair toda a dimensão fantástica em Macbeth, porque "o mal não é fantástico mas se esconde nas coisas ordinárias", para retomar as palavras do encenador publicadas em nosso número de março de 2009 (ver O.M. n 38 p. 36). As feiticeiras são aqui substituídas por multidão anônima em impermeável, anoraque ou pelerine que, após haver incitado Macbeth a galgar as barreiras da escala social recorrendo ao assassínio, acaba por rejeitá-lo como um ser daninho, quando descobre que ele se transformou em tirano. ${ }^{8}$ (grifo meu) 
Mais adiante (p. 64), descrição exata de importante elemento do cenário criado pelo diretor:

Graças a um sistema de travellings e de zooms aéreos projetados em uma tela gigantesca no proscênio, [...] o espectador viaja pelos diferentes locais de um burgo situado no meio do campo, com duas referências principais: a praça onde a multidão se reúne, de um lado, com suas pequenas casa cinzas alinhadas [...] e seus lampiões; e a morada dos Macbeth, de outro, da qual se apresenta o teto, depois a fachada, e por fim o interior da sala de jantar, vista através de uma janela.

\section{$[\ldots]$}

A praça servirá até o final aos ajuntamentos dos habitantes da aldeia, acolhedores em relação a Macbeth no primeiro ato, depois vítimas de suas exigências (expulsos de suas casas, eles arrastam suas malas durante "Pátria oppressa"), e enfim revoltados contra ele. ${ }^{9}$ (grifo meu)

O entusiasmo do editor levou-o a inserir entre o editorial e a resenha, no $\mathrm{n}^{\circ} 38$ da revista, entrevistas com o regente e com o diretor, esta ainda mais esclarecedora de sua concepção e soluções cênicas.

Agora, o confronto entre o material impresso e o que vi do filme-de-ópera.

Pareceu-me, em linhas gerais, correta a parte analítica dos textos. Excessivo, contudo, o louvor ao produto global.

Alguns problemas do esforço de atualização muito bem resolvidos. Por exemplo, a louvada projeção inicial, com a vista aérea da aldeia, golpe de mestre. Da mesma forma, de extrema eficiência a direção de atores.

No entanto, difícil me foi reconhecer, na montagem, a concepção básica do autor. A menos se disponha das informações ou explicações fornecidas por Martet especialmente as contidas nos trechos que grifei. A substituição das feiticeiras pelo mundéu de pessoas comuns e suas relações com Macbeth, por exemplo, souberam-me inteiramente obscuras.

Como também outra vertente da resenha: a psicologia da relação entre as personagens principais e sua evolução ao longo do drama. Em passagens que não transcrevi, o editor da revista exalta a inteligência de Tcherniakov na construção do jogo psicológico entre eles. Não me soou convincente aquilo que, nas atitudes e comportamentos dos protagonistas definidos pelo diretor, o editor francês enxergou e citou como evidências lógicas deste jogo.

O cineasta do filme-de-ópera, presente à exibição nos Correios, deu testemunho da fidelidade das tomadas, assegurada pela direta supervisão do encenador sobre a câmera e sobre a escolha dos ângulos. Aceito o pressuposto, as divergências acima se 
explicam, talvez, por minha própria deficiência perceptiva. Contudo, não se descarte a hipótese: a apresentação da ópera, em Novossibirski como em Paris, pode haver sido precedida da distribuição de rico programa de espetáculo; neste, o conteúdo de praxe pode ter sido acrescido de texto assinado pelo diretor, esclarecendo aspectos de sua visão. É procedimento mais e mais comum. Por lá.

Observação final sobre a resenha crítica: em tão extenso material, apenas breve apreciação sobre os intérpretes - aqui o "como queria demonstrar", prometido ao referir a importância relativa hoje atribuída aos papéis dos profissionais envolvidos na produção.

Ênfase imprescindível: nenhuma análise quanto à adequação da música de Verdi à nova compreensão da trama. Como se a componente sonora cumprisse papel ilustrativo. Como se importante fosse, acima de tudo, a originalidade de um novo entendimento da tragédia que Shakespeare escreveu no século XVII. Apesar de o novo, neste caso, haver sido desenvolvido sobre um texto já extraído do original segundo a sensibilidade e a inteligência de duas mentes do século XVIII (Piave, o libretista, trabalhou sob orientação explícita de Verdi). Qual!!!

A publicação das partituras das óperas, no passado, costumava apresentar a obra como de autoria do libretista, com música do compositor. Todavia, o nome deste último e os dos cantores foram sempre o grande chamariz para atrair o público aos teatros. Sob a égide do Efêmero, não tarda e o modelo dos anúncios trará, após o título da ópera, a rubrica "Espetáculo de (Nome do Encenador)". Só depois serão indicados, com precedência variável, os demais responsáveis pelo resultado.

P.S.

Escrevi acima:

"Desde o transistor e a técnica digital, todo desenvolvimento tecnológico voltado à redução da vida útil, à substituição de produtos, à criação de novas pretensas "utilidades"; tudo, num átimo, feito velho, obsoleto, superado - menos a vida do ente consumista, protegida, cuidada, esticada".

Acrescento:

Esta evolução seguiu uma senda que veio desaguar na Internet, propícia à criação de utilidades "virtuais", ainda mais tributárias do Efêmero que o Espetáculo "real". As propriedades técnicas de espantosas velocidades e capacidades de armazenamento abrem espaço ao Paroxismo do Efêmero. 
Entretanto a Internet tem outras faces. A acessibilidade de suas "redes sociais" está criando formas de relacionamento novas, de repercussões, para o contexto social, ainda difíceis de avaliar. $\mathrm{E}$ as mesmas altas velocidades e processos de armazenamento e recuperação de inédita eficiência predispõem a Memória da Humanidade a engrandecimento insuspeitado. Com isso, podem propiciar a Celebração do Perene em contraponto ao Efêmero.

A espécie humana necessita, com urgência, teóricos humanistas de gênio. A Ópera também, como foram seus inventores em 1600.

1 "Esquerdismo, doença infantil do comunismo", de Vladimir llich Uliánov (Lênin).

${ }^{2}$ Evidentemente, "A Crise" deflagrada pelo estouro da "bolha imobiliária" americana abalou tudo. Mas os contornos relativos expostos neste parágrafo parecem os mesmos. A deterioração na Itália, por exemplo, é anterior.

${ }^{3} \mathrm{O}$ "quase sempre" deve-se à escola veneziana, segunda metade do século 17. Era de rigor, então, o emprego de grandes e complexas máquinas para a produção de "efeitos especiais" (deuses descendo dos céus sobre nuvens, por exemplo).

${ }^{4}$ Cenógrafa e diretora teatral estadunidense, aclamada por adaptações para o palco a partir de fontes não dramatúrgicas: espetáculos baseados em As mil e uma noites (1992), em manuscritos de Leonardo da Vinci (1994), em Marcel Proust (1995) e na Odisséia (1999) exemplificam. Em 2002 recebeu um Tony Award por melhor direção teatral em Metamorfoses, que adaptou do poema de Ovídio. Em ópera, pouco antes do Tony, trabalhou com o compositor Philip Glass: dirigiu a estréia de Galileo Galilei e co-assinou o libreto, em parceria com o próprio autor e Arnold Weinstein.

${ }^{5}$ Em Lucia: soprano russo Anna Netrebko; tenor polonês Piotr Beczala. Em La Sonnambula: soprano francês Natalie Dessay; tenor peruano Juan Diego Flores. Demais papéis à altura, orquestra e coro famosos do Met, regência de Evelino Pidò, La Sonnambula, e Marco Armiliato, Lucia di Lammermoor.

${ }^{6}$ The Bride of Lammermoor, de 1819.

7 "[...] la cohérence de la démarche, l'intelligence de la direction d'acteurs, les correspondances avec le texte et la musique, ainsi qu'une manière de s'imposer au spectateur sans l'assommer ni l'agresser, justifient chaque geste, chaque image... L'important, c'est qu'avec des parts pris discutables mais clairement assumés - notamment celui d'évacuer toute la dimension fantastique de l'intrigue et de faire des deux principaux personnages un Monsieur e une Madame Toute-leMonde, Tcherniakov propose une interprétation passionante des rapports à l'intérieur du couple (amour, admiration, ressentiments, dépendance...) et de l'engrenage des meurtres (c'est en fait le corps social, des le départ hostile envers Macbeth, qui lui souffle l'idée du crime, pour l'expulser à la fin comme un êtte malfaisant). Tous les repères traditionnels se brouillent: Lady Macbeth n'est plus l'unique instigatrice, Macbeth n'est plus seulement un être faible manipulé par sa femme, l'opprimé peut être en même temps l'oppresseur, le bourreau et la victime ne son pas forcément ceux que l'on croi [...]." As comparações colocadas pelo autor do texto referem-se, naturalmente, ao libreto da ópera, não à tragédia shakespeariana.

8 "Lês partis pris de Dimitri Tcherniakov, nous l'avons dit et nous le répétons, sont éminement discutables et nous n'avons pas été surpris que des sifflets se méllent aux tonerres d'applaudissements au rideau final, le soir de la première. Mais ils ont le double mérite d'être clairémentassumés et défendis avec une cohérence implacable. II est particulièrement risqué, par 
exemple, d'évacouer toute la dimension du fantastique dans Macbeth, au motif que "le mal n'est pas fantastque mais se cache dans les choses ordinaires", pour répandre les propos du metteur en scène publiés dans notre numéro de mars 2009 (voir O.M. $n^{\circ} 38$ p. 36). Les sorcières sont ici remplacées par une foule anonyme en impermeable, doudonne ou duffe-coat qui, aprés avoir incité Macbeth à gravir des barraux de l'échelle sociale en recourrant au meurtre, finit par lerejeter comme un être malfaisant, lorsqu'elle découvre qu'il s'est transformé en tyran". Opéra Magazine, $\mathrm{N}^{\circ} 40$, maio de 2009 , p. 63.

9 "Grâce à un système de travellings et de zooms aériens projetés sur un écran géant à l'avantscène... le spectateur voyange en différents endroits d'un bourg posé au milieu de la campagne, avec deux repères principaux: la place où se réunit la foule d'un coté, avec ses petites maison grises tout droit... et ses réverbères, le domicile des Macbeth de l'autre, dont on découvre le toit, puis la façade, et enfin l'intérieur de la salle à manger, vu à trevers une fenêtre. [...] La place servira jusqu'au bout aux rassemblements des habitants du village, bienveillants envers Macbeth au premier acte, puis victimes de ses exactions (chassés de leurs maison, ils traînent leurs valises derrière eux pendant 'Patria oppressa') et enfin révoltés contre lui". 